www.jmscr.igmpublication.org

Impact Factor 5.84

Index Copernicus Value: 83.27

ISSN (e)-2347-176x ISSN (p) 2455-0450

crossref DOI: _https://dx.doi.org/10.18535/jmscr/v5i8.126

Journal Of Medical Science And Clinical Research

IGM Publication

An Official Publication of IGM Publication

\title{
Role of Soluble Vascular Cell Adhesion Molecule-1 in Knee Osteoarthritis among Postmenopausal Women
}

\author{
Authors \\ Reetika Shrivastava $^{1 *}$, Y.S.Chandel ${ }^{2}$
}

${ }^{1}$ Dept of Biochemistry, Gajra Raja Medical College and J.A. Group of Hospitals, Gwalior (M.P.), India

${ }^{2}$ Department of Obstetrics and Gynaecology, Army College of Medical Sciences, New Delhi, India

*Corresponding Author

Reetika Shrivastava

Email: reetika.shrivastava87@gmail.com

\begin{abstract}
Objective: Knee osteoarthritis is the most common form of joint disorder and a leading cause of pain and functional disability among elderly female population or in postmenopausal phase of females. Osteoarthritis is now considered as a low grade inflammatory condition. VCAM-1 is an inducible cell surface glycoprotein and mediates heterotypic cellular aggregation. Therefore, the aim of this study is to assess the role of soluble VCAM-1in knee osteoarthritis among postmenopausal women.

Materials and Methods: The present study includes 100 postmenopausal women of age 50 years or above with clinical symptoms of knee osteoarthritis as cases and 100 normal healthy female age matched individuals as controls. CRP was assayed in serum by using latex-enhanced turbidimetric immunoassay method. Soluble VCAM-1 and estrogen were estimated by ELISA method in all 200 subjects. Statistical analysis was made by student independent sample t-test. Correlation was determined by using spearman's rank correlation coefficient.

Result: The serum level of soluble VCAM-1 was found statistically highly significantly increased $(p<0.001)$ while estrogen was found highly significantly decreased $(p<0.001)$ in postmenopausal women with symptoms of knee osteoarthritis as compared to control healthy subjects. CRP was also found significantly increased in postmenopausal women with symptoms of knee osteoarthritis as compared to control healthy subjects. A correlative study showed significant negative correlation between VCAM-1 and estrogen hormone while positive correlation between VCAM-1 and CRP in postmenopausal women with symptoms of knee osteoarthritis.

Conclusion: The increased levels of soluble VCAM-1 showed an active inflammation or cartilage damage. Thus, it can be used as a biomarker for the assessment of onset of osteoarthritis.

Keywords: VCAM-1, Knee osteoarthritis, Postmenopausal women, Estrogen.
\end{abstract}

\section{Introduction}

Osteoarthritis is the most common joint disorder and one of the leading causes of pain, functional disability and reduced health-related quality of life. It is characterized by slow progressive degeneration of articular cartilage, subchondral bone sclerosis, synovial inflammation and marked osteophyte formation, with the involvement of whole joint. ${ }^{[1]}$ Epidemiological observations showed that after the age of 50, osteoarthritis, 
particularly of the knee, is more common in women than in men and suggesting that estrogen deficiency may play an important role in the onset or progression of osteoarthritis. ${ }^{[2-4]}$ Clinically, this condition is characterized by joint pain, tenderness, limitation of movement, crepitus, occasional effusion, and variable degrees of local inflammation. For a long time osteoarthritis was considered as non-inflammatory condition, but now it become evident that low grade of inflammation mainly associated with synovitis has been reported in osteoarthritis. ${ }^{[5-8]}$ Synovitis is commonly seen in early and advanced phase of osteoarthritis and has been associated with knee pain and cartilage degeneration. $\left.{ }^{[9-12]}\right]$ C-reactive protein (CRP) serving as a marker for systemic inflammation, several studies showing a relationship between serum CRP levels and osteoarthritis of the knee. ${ }^{[13-15]}$ Although, CRP is not taken as an optimal marker for inflammation in osteoarthritis; other putative markers have been associated with some osteoarthritis phenotypes. These include proinflammatory cytokines, cell adhesion molecules and adiponectin. The inflammatory changes occur in the synovium include synovial hypertrophy and hyperplasia with infiltration of the underlying tissue by various inflammatory cells. ${ }^{[16-19]}$ Adhesion molecules play an important role during inflammatory process because they enable inflammatory cells to migrate to inflamed compartment. Vascular cell adhesion molecule-1 is an inducible cell surface sialoglycoprotein expressed on chondrocytes and synovial fibroblasts. VCAM-1 mediates the adhesion of lymphocytes, monocytes, eosinophils, and basophils to vascular endothelium and plays a role in the development of inflammation. [20] Therefore, the aim of this study is to assess the role of soluble VCAM-1 in postmenopausal women to detect early stage of knee osteoarthritis.

\section{Materials and Methods}

The present study has been carried out in the Department of Biochemistry and Department of Orthopaedics, G.R Medical College \& J.A. Group of Hospitals, Gwalior. Total 200 human subjects were taken in the study. Out of which 100 postmenopausal women with symptoms of knee osteoarthritis were taken as cases and 100 normal healthy individuals of same age as control.

Inclusion criteria: Postmenopausal women having no menstruation for more than 12 months with complain of knee pain lasting longer than 1 month in addition to atleast 3 of the following 6 criteria according to American College of Rheumatology Criteria for knee osteoarthritis: age $>50$ years, morning stiffness more than 30 minutes, crepitus, bony enlargement, bony tenderness and absence of palpable warmth.

Exclusion criteria: Patients taking any hormone replacement therapy (HRT), non steroidal anti inflammatory drugs (NSAID), having any metabolic bone disease, rheumatoid arthritis, serious systemic diseases, history of knee trauma or knee injury, cardiac heart diseases, diabetes. Before starting analysis, the written consent was taken from all subjects. The study has been approved by institutional ethical committee and was carried out by keeping all norms in mind. The clinical manifestations of disease, personal history of patients were recorded in study proforma.

$7 \mathrm{ml}$ of blood sample was taken from all subjects under all aseptic precautions. Blood sample was collected in plain vial and incubated at $37^{\circ} \mathrm{C}$ for 30 minutes. After incubation, clot was removed and remaining sample was taken in centrifuge test tube. Samples were centrifuged at 3000 rpm for 10 to 20 minutes. Supernatant was collected in clean and dry serum test tube and stored at $-20^{\circ} \mathrm{C}$ for further estimation of $\mathrm{C}$ - reactive protein, estrogen hormone and soluble vascular cell adhesion molecule-1(sVCAM-1). CRP was assayed in serum by latex-enhanced turbidimetric immunoassay. The serum level of soluble VCAM1 level and estrogen hormone were estimated by ELISA technique. The results were expressed as Mean \pm Standard Deviation .The statistical differences between cases and control were determined by student independent t-test. Correlation was determined by using spearman's 
rank correlation coefficient. Data analyses were performed with the Statistical Package for the Social Sciences, version 21.0 (SPSS, Chicago, Illinois, USA). The $\mathrm{p}$ value less than 0.05 were considered as significant.

\section{Results}

Table No 1: showing the status of CRP, estrogen hormone and soluble VCAM-1 level in control and postmenopausal women with symptoms of knee osteoarthritis (cases). The mean level of CRP was found significantly increased $(\mathrm{p}<0.01)$ while the serum levels of soluble VCAM-1 was found statistically highly significantly increased $(p<0.001)$ and estrogen hormone was found highly significantly decreased $(p<0.001) \quad$ in postmenopausal women with symptoms of knee osteoarthritis as compared to control. Table No 2: showing the inverse correlation between soluble VCAM-1 and estrogen hormone while positive correlation between soluble VCAM-1 and CRP in postmenopausal women with symptoms of knee osteoarthritis.

Table No 1: Showing the level of sVCAM-1, estrogen and CRP in control and postmenopausal women with clinical symptoms of knee osteoarthritis

\begin{tabular}{|l|c|c|}
\hline Variable & Control (100) & $\begin{array}{c}\text { OA Subjects } \\
(100)\end{array}$ \\
\hline $\begin{array}{l}\text { Estrogen } \\
(\mathrm{pg} / \mathrm{ml})\end{array}$ & $36.19 \pm 15.80$ & $27.31 \pm 17.29^{* *}$ \\
\hline $\mathrm{CRP}(\mathrm{mg} / \mathrm{l})$ & $4.6 \pm 1.67$ & $6.6 \pm 5.78^{*}$ \\
\hline sVCAM- & $464.31 \pm$ & $562.87 \pm 63.78^{* *}$ \\
$1(\mathrm{ng} / \mathrm{ml})$ & 28.54 & \\
\hline
\end{tabular}

Significant at $\mathrm{p}<0.01,{ }^{* *}$ HighlySignificant at $\mathrm{p}<0.001$

Table No 2: Showing correlation between sVCAM-1 and other investigated parameters in postmenopausal women with symptoms of knee osteoarthritis:

\begin{tabular}{|l|c|c|}
\hline S.No & Parameters & VCAM-1 \\
\hline 1. & CRP & $0.329^{*}$ \\
\hline 2. & Estrogen & $-0.281^{*}$ \\
\hline
\end{tabular}

Results are presented in $r$ value

${ }^{*}$ Significant at $\mathrm{p}<0.01$

\section{Discussion}

Osteoarthritis is now considered as a whole joint disease in which bone, synovia and other joint structures are affected and adhesion molecules in the circulation contribute to the pathogenesis of osteoarthritis through cell-cell or cell-matrix interactions. In our study, the mean level of serum soluble VCAM-1 was found statistically highly significant $(p<0.001)$ in postmenopausal women with symptoms of knee osteoarthritis as compared to control (Table No 1). This is consistent with the study of Hoeven et al who reported the increased level of VCAM-1 in elderly women having knee osteoarthritis than those without knee osteoarthritis. ${ }^{[21]}$ Other studies also reported the elevated level of soluble VCAM-1 in serum of patients with osteoarthritis. ${ }^{[22-24]}$ In joints, VCAM-1 is expressed by microvascular endothelial cells, synovial fibroblasts, and chondrocytes. ${ }^{[25]}$ It is not appreciably expressed on resting vascular endothelium but is rapidly induced in response to a number of inflammatory stimuli, such as TNF-a, IL-1 $\beta .{ }^{[26]}$ During cartilage damage, chondrocytes can produce or respond to a large number of cytokines such as tumor necrosis factor- $\alpha$ and interleukin-1 $\beta .{ }^{[27]}$ These proinflammatory cytokine activation alters the phenotype of quiescent endothelial cells, which in turn increases the synthesis of VCAM-1. ${ }^{[28]}$ The increased level of soluble VCAM-1 in our study shows active cartilage damage or an inflammatory component in osteoarthritis. The cartilage is the prime site of osteoarthritis disease and is very sensitive to change in sex hormone level. Our study showed significant decreased levels of estrogen hormone $(p<0.001)$ in postmenopausal female subjects with symptoms of knee osteoarthritis as compared to control postmenopausal women. This is in agreement with the studies of Sheikh et al ${ }^{[29]}$. The correlative study between VCAM-1 and estrogen hormone showed an inverse relationship between them. It may be due to depletion of estrogen hormone during menopause, which induces VCAM-1 production. The mechanism through which estrogen decreases cytokine induced 
VCAM-1 production by inhibition of NF- $\kappa \beta$, AP1 and GATA transcription factors. ${ }^{[30]}$ In this study the serum level of CRP was also found significantly high in postmenopausal women with symptoms of knee osteoarthritis as compared to control which is in consistent with the study of Spector et al who reported modestly but significant increase of CRP level in women with early stage of knee osteoarthritis ${ }^{[14]}$. CRP is an acute phase protein, which reflects a measure of the acute-phase response. Elevated level of CRP in serum may reflect subclinical inflammation in affected joints, mediated by cytokines. Furthermore we also found a positive correlation between CRP and VCAM-1 in this study. Thus, these findings support that inflammation is a component of the early events leading to clinical osteoarthritis.

\section{Conclusion}

It is therefore concluded from the study that in postmenopausal women lack of estrogen hormone induces soluble VCAM-1 production. VCAM-1 mediates the interaction of chondrocytes with immune cells and could thus by itself contribute to immune-mediated cartilage damage. Hence, serum level of soluble VCAM-1 could be used as an early biomarker for inflammatory response and cartilage damage in osteoarthritis. If in postmenopausal women the periodic check up for estrogen and VCAM-1 is carried out the occurrence and severity of osteoarthritis could be prevented.

\section{References}

1. Hunter DJ, Felson DT. Osteoarthritis. BMJ 2006;332:639-642.

2. Sangha O. Epidemiology of rheumatic diseases. Rheumatology

(Oxford) 2000;39:3-12.

3. Hart DJ, Doyle DV, Spector TD. Incidence and risk factors for radiographic knee osteoarthritis in middle-aged women: the Chingford Study. Arthritis Rheum 1999;42:17-24.
4. Nevitt MC, Cummings SR, Lane NE, Hochberg MC, Scott JC, Pressman AR, et al. Association of estrogen replacement therapy with the risk of osteoarthritis of the hip in elderly white women. Arch Intern Med 1996;156:2073-2080.

5. Konttinen YT, Sillat T, Barreto G, Ainola M, Nordstrom DC. Osteoarthritis as an autoinflammatory disease caused by chondrocyte-mediated inflammatory responses. Arthritis Rheum 2012;64:613-6.

6. Saxne T, Lindell M, Mansson B, Petersson IF, Heinegard D. Inflammation is a feature of the disease process in early knee joint osteoarthritis. Rheumatology (Oxford) 2003;42:903-4.

7. Smith MD, Triantafillou S, Parker A, Youssef PP, Coleman M. Synovial membrane inflammation and cytokine production in patients with early osteoarthritis. J Rheumatol 1997;24:36571.

8. Pelletier JP, Martel-Pelletier J, Abramson SB. Osteoarthritis, an inflammatory disease: potential implication for the selection of new therapeutic targets. Arthritis Rheum 2001;44:1237-47.

9. Benito MJ, Veale DJ, FitzGerald O, van den Berg WB, Bresnihan B. Synovial tissue inflammation in early and late osteoarthritis. Ann Rheum Dis 2005;64:1263-7.

10. Goldring SR, Goldring MB. The role of cytokines in cartilage matrix degeneration in osteoarthritis. Clin Orthop Relat Res 2004;:S27-36.

11. Hill CL, Hunter DJ, Niu J, Clancy M, Guermazi A, Genant H, et al. Synovitis detected on magnetic resonance imaging and its relation to pain and cartilage loss in knee osteoarthritis. Ann Rheum Dis 2007;66:1599-603.

12. Ayral X, Pickering EH, Woodworth TG, Mackillop N, Dougados M. Synovitis: a potential predictive factor of structural 
progression of medial tibiofemoral knee osteoarthritis - results of a 1 year longitudinal arthroscopic study in 422 patients. Osteoarthr Cartil 2005;13:361-7.

13. Sharif M, Elson CJ, Dieppe PA, Kirwan JR. Elevated serum C-reactive protein levels in osteoarthritis. $\mathrm{Br} \mathrm{J}$ Rheumatol 1997;36:140-1.

14. Spector TD, Hart DJ, Nandra D, Doyle DV, Mackillop N, Gallimore JR et al. Low-level increases in serum $\mathrm{C}$-reactive protein are present in early osteoarthritis of the knee and predict progressive disease. Arthritis Rheum 1997;40:723-7.

15. Wolfe F. The C-reactive protein but not erythrocyte sedimentation rate is associated with clinical severity in patients with osteoarthritis of the knee or hip. J Rheumatol 1997;24:1486-8.

16. Prieto-Potin I, Largo R, Roman-Blas JA, Herrero-Beaumont G, Walsh DA. Characterization of multinucleated giant cells in synovium and subchondral bone in knee osteoarthritis and rheumatoid arthritis. BMC Musculoskelet Disord 2015;16:226.

17. Klein-Wieringa IR, de Lange-Brokaar BJ, Yusuf E, Andersen SN, Kwekkeboom JC, Kroon HM, et al. Inflammatory cells in patients with endstage knee osteoarthritis: a comparison between the synovium and the infrapatellar fat pad. J Rheumatol 2016;43(4):771-8.

18. Deligne C, Casulli S, Pigenet A, Bougault C, Campillo-Gimenez L, Nourissat G, et al. Differential expression of interleukin17 and interleukin-22 in inflamed and noninflamed synovium from osteoarthritis patients. Osteoarthr Cartil 2015;23(11):1843-52.

19. de Lange-Brokaar BJ, Ioan-Facsinay A, van Osch GJ, Zuurmond AM, Schoones J, Toes RE, et al. Synovial inflammation, immune cells and their cytokines in osteoarthritis: a review. Osteoarthr Cartil 2012;20(12):1484-99.

20. MULLER WA: Mechanisms of transendothelial migration of leukocytes. Circ Res 2009;105: 223-30.

21. Hoeven TA, Kavousi M, Ikram MA, van Meurs JB, Bindels PJ, Hofman A, et al. Markers of atherosclerosis in relation to presence and progression of knee osteoarthritis: a population-based cohort study. Rheumatology(Oxford) 2015;54(9):1692-8.

22. Kalichman L, Pantsulaia I, Kobyliansky E. Association between vascular cell adhesion molecule-1and radiographic hand osteoarthritis. Clin Exp Rheumatol 2011;29:544-546.

23. Nell-Duxneuner V, Axmann R, HusarMemmer E, Dallos T, Datz C, Stadlmayr $\mathrm{A}$, et al. VCAM-1 serum levels are associated with arthropathy in hereditary haemochromatosis. Ann Rheum Dis 2013;72:2006-10.

24. Schett G, Kiechl S, Bonora E, Zwerina J, Mayr A, Axmann R, et al. Vascular cell adhesion molecule 1 as a predictor of severe osteoarthritis of the hip and knee joints. Arthritis Rheum 2009;60(8):2381-9.

25. Kriegsmann J, Keyszer GM, Geiler T, Brauer R, Gay RE, Gay S. Expression of vascular cell adhesion molecule-1 mRNA and protein in rheumatoid synovium demonstrated by in situ hybridization and immunohistochemistry. Lab Invest 1995;72:209-14.

26. Kienzle G, von Kempis J. Vascular cell adhesion molecule 1 (CD106) on primary human articular chondrocytes: functional regulation of expression by cytokines and comparison with intercellular adhesion molecule 1 (CD54) and very late activation antigen 2. Arthritis Rheum 1998;41:1296305.

27. Goldring MB, Otero M, Tsuchimochi K, Ijiri K, Li Y. Defining the roles of 
inflammatory and anabolic cytokines in cartilage metabolism. Ann Rheum Dis 2008; 67 (Suppl.3):75-82.

28. Osborn L, Hession C, Tizard R, Vassallo C, Luhowskyj S, Chi-Rosso $G$, et al. Direct expression cloning of vascular cell adhesion molecule 1, a cytokine-induced endothelial protein that binds to lymphocytes. Cell 1989;59:1203-11.

29. Sheikh SI, Khanam A. Osteoarthritis in postmenopausal women. World J Pharm Sci 2014;21:49-51.

30. Simoncini T, Maffei S, Basta G, Barsacchi G, Genazzani AR, Liao JK, et al. Estrogens and glucocorticoids inhibit endothelial vascular cell adhesion molecule-1 expression by different transcriptional mechanisms. Circ Res 2000;87:19-25. 